\title{
The Evaluation of the Nutritional Status in Patients with Irritable Bowel Syndrome
}

\author{
Birsen Yilmaz (D), Gamze Akbulut \\ Gazi University Faculty of Health Sciences, Department of Nutrition and Dietetics, Ankara/Turkey.
}

Correspondence Author: Birsen Yilmaz

E-mail: dytbirsen@gmail.com

Received: $13.11 .2019 \quad$ Accepted: 09.03.2021

\begin{abstract}
Objective: Irritable bowel syndrome (IBS) is one of the most common chronic functional diseases of the gastrointestinal tract. There is no organic disorder in IBS. The pathogenesis of IBS is not fully understood. Although the symptoms of IBS patients are mostly diet-related, there are not many studies evaluating nutrient intake. In this study, it was aimed to determine nutrient intake and nutrition habits of IBS patients.

Methods: A total of 70 IBS patients, 52 females and 18 males, were included in the study. Three-day food records were compiled. Besides, foods that reduced symptoms of IBS and foods that caused sitophobia were interrogated in the study.

Results: The mean age of the patients was $37.8 \pm 10.03$ years and $40 \%$ of them were IBS-mixed subtype. Daily intake of energy and some nutrients were found to be similar to the recommended levels. The mean intake of energy, protein, carbohydrate, saturated fatty acid, vitamin B1, vitamin B2, vitamin B6, vitamin B12, calcium, magnesium, phosphorus, iron, copper ( $<<0.001$ ), total folic acid, carotene, sodium, and potassium $(p<0.05)$ showed statistically significant differences according to gender. It was determined that $85.7 \%$ of the patients had sitophobia. In both genders, apricot was the most reported food to have reduced IBS symptoms. The foods causing sitophobia were raw vegetables-fruits (35.7\%), spicy foods (34.3\%), and legumes (27.1\%).

Conclusions: Although IBS avoids consuming certain foods for fear of increasing their symptoms, energy, and nutrient intake is found to be similar to generally recommended levels.
\end{abstract}

Keywords: diet, gastrointestinal diseases, irritable bowel syndrome, nutrition, nutrition habits

\section{INTRODUCTION}

Irritable bowel syndrome (IBS) is a chronic functional bowel disease without a clinically organic pathology. It is characterized by lower and upper gastrointestinal symptoms such as a change in bowel habits (constipation/diarrhea), abdominal pain, dyspeptic complaints (gas, bloating, and mist). However, the etiology of IBS is not fully understood (1). While IBS is often seen in young adults, it may be encountered in different age categories. Irritable bowel syndrome, which is one of the reasons for applying to a physician in primary health care institutions, is also a frequent disease in gastroenterology polyclinics. As per epidemiological data, the frequency of the disease is higher in females than in males. The majority of IBS patients are between 20 and 40 years of age. It has been reported that the frequency of this disease in the general population globally is $5-20 \%$ (2). The prevalence in Western populations is $8-23 \%, 60-70 \%$ of which are female. It is most commonly seen between the ages of 30-50 (3-5). The country with the lowest prevalence rate is Singapore
$(2.3 \%)$, while the country with the highest prevalence rate is reported to be Niger (30\%). In Asian countries, $1 \%$ to $10 \%$ of the population has symptoms consistent with IBS (4). In studies carried out in different regions of Turkey, IBS frequency was determined as $2.7-19.1 \%(6-8)$.

Although IBS may not be fatal, it seriously lowers the quality of life (QoL) of patients and increases the levels of depression and anxiety. In recent studies, it has been shown that the low fermentable oligo-, di-, and monosaccharides and polyols (FODMAP) diet administered in intestinal diseases reduces the symptoms of illness (especially inflammatory bowel disease and IBS) and also changes intestinal motility and secretion. FODMAP includes fructans, galacto-oligosaccharides - oligosaccharides, lactosedisaccharide, fructose-monosaccharide especially over glucose, mannitol, sorbitol, maltitol, and xylitol-polyols. Observational cohort studies in the 1980s and 1990s found that the low FODMAP diet reduced symptomatic 
complaints. Current studies confirm this finding. Looking at the historical process of the term FODMAP, it was used by a group of Australian researchers in 2005 and is frequently mentioned in the scientific literature $(9,10)$. On the other hand, there are some different diet models for IBS such as a gluten-free diet. Although diet has an important role in both IBS pathophysiology and treatment management, it is recommended that a sustainable diet that patients can adapt to in the long term should be arranged according to nutritionists and the patient's nutritional habits.

The low FODMAP diet is based on the principle of reducing the fermented oligosaccharides, disaccharides, monosaccharides, and polyols in the diet. FODMAP expresses all short-chain carbohydrates. These carbohydrates are thought to increase the symptoms because they are known to be absorbed poorly and ferment rapidly in the intestine (11). Diets containing low FODMAP have been shown to reduce gastrointestinal symptoms when compared to diets containing high FODMAP (24). Also, diets containing low FODMAP improve the QoL of patients, positively affect intestinal microbiota and gastrointestinal endocrine cells (1214).

On investigation of studies to date, insufficient data is encountered about the dietary changes of IBS patients assessed, the effects of nutrient deficiencies, and the dietary changes on the symptoms of patients. This study aims to evaluate the nutritional status of IBS patients and shed light on providing novel recommendations for them.

\section{METHODS}

\subsection{Study Subjects}

The data were collected from 70 volunteers ( 52 females, 18 males) between 20-55 years who were admitted to Ankara Numune Training and Research Hospital Gastroenterology Polyclinics and diagnosed with IBS according to Rome III Criteria. This study was conducted between February and September 2016.

Patients who were able to choose nutrients on their own, who did not have perception impairment and communication problems were included in the study. Patients with inflammatory bowel disease, celiac disease, who are known to have lactose intolerance, advanced cardiac, respiratory, renal, hepatic disorders, malignancy, major psychiatric disorder, and narcotic/alcohol use were not included in the study. Apart from uncomplicated appendicitis, patients who underwent previous abdominal surgery, pregnant and lactating patients were excluded from the study.

\subsection{Anthropometric Measures}

Anthropometric measurements (body weight $(\mathrm{kg})$, height $(\mathrm{cm})$, waist circumference $(\mathrm{cm})$, hip circumference $(\mathrm{cm}))$ of the subjects participating in the study were measured by the researcher. Bodyweight measurements were analyzed using the Tanita BC 532 bioelectrical impedance device in an empty stomach in the morning with minimal clothing on the individual. Height was measured on the head Frankfurt plane with the individuals' feet together. The body mass index (BMI) was calculated as the bodyweight/height ${ }^{2}$ ( $\mathrm{kg} /$ $\mathrm{m}^{2}$ ) (15). Prior to waist circumference measurements, the patients were asked to took off the clothing and objects that might prevent measurement. The measurement was taken at the position where the abdomen was loose while the arms stood on two sides and the feet placed side by side facing the person recording the measurements. Between the lowest rib bone and the crista iliaca, the circumference passing through the middle point was measured by a non-stretching tape. Measurements were recorded in $\mathrm{cm}$ and with a sensitivity of $0.1 \mathrm{~cm}$. Measurement of the hip circumference was taken from the widest region of the hip (16).

\subsection{Dietary Assessment}

To determine dietary energy and nutrient intake of the individual, three-day foods records (three consecutive days one day at the end of the week) were compiled by dieticians so that individuals could take the changes into account in weekly nutrient consumption. The daily intake of energy and nutrients were evaluated using a Nutrient Data Base Program (BeBiS, version 7.0; Pasifik Company, Istanbul, Turkey), adapted for Turkish individuals (17).

To evaluate the eating habits of the patients, the consumption frequency of different foods was examined before and after the diagnosis of IBS. The questionnaire interrogated the frequency of consumption of 43 food types (dairy products, fruits, vegetables, drinks, etc.) over the previous 12 months. Participants had six choices to indicate the frequency of consumption of each of the 43 foods from "never" to "per day". Foods that aggravated the symptoms (raw vegetablesfruits such as potato, carrot, citrus; dairy products such as milk, yoghurt, drinks, legumes, etc.) in IBS patients were given wide coverage in food frequency questionnaire based on the studies conducted with IBS patients prior to this study. In addition, IBS symptoms were taken into account when food was grouped. For example, fruits were grouped as follows: citrus; apples, peaches, quince and bananas; other fruit and dried fruits. In this way, it was aimed to evaluate whether there was any change in the frequency of food consumption before and after the diagnosis of IBS. Besides, the foods that the individuals thought alleviated or aggravated their symptoms were questioned. The questions in this section were asked in open-ended fashion so that patients would not be biased.

\subsection{Statistical analysis}

Statistical Package for the Social Sciences (SPSS) 22.0 package program was used to evaluate the data (18). For descriptive analyses, frequencies and percentages were used for qualitative observations and Chi-square analyses 
were utilized for interpretations. Mann Whitney $U$ test was also employed in the two groups considering the number of observations for quantitative observations. P-values less than 0.05 were considered statistically significant.

\section{RESULTS}

Participant characteristics were shown in Table 1. In total, 70 subjects with IBS participated in the study, $26 \%$ of whom (18) were males and $74 \%$ (52) were females. The mean age of the subjects was $37.8 \pm 10.03$ years, the mean diagnosis time of IBS is $6.5 \pm 17.47$ years. There was no significant difference between gender in mean age and diagnosis time. The percent of alternating IBS symptoms (IBS-M) and constipation-predominant symptoms (IBS-C) was approximately the same $(37.1 \%$ and $40.0 \%$, respectively), while diarrhea-predominant symptoms (IBS-D) ratio was $22.9 \%$. Although IBS-M was seen more frequently in males, in females, IBS-C and IBS-M were more frequent than the other type. Male subjects had a mean body mass index (BMI) of $27.1 \pm 2.97 \mathrm{~kg} / \mathrm{m}^{2}$ and were not significantly different from females $\left(26.6 \pm 5.81 \mathrm{~kg} / \mathrm{m}^{2}\right)$. Most of the individuals were married (\%68.6) and $35 \%$ of them were primary school graduates. More than half of the participants $(57.1 \%)$ had at least 8 years of formal education. There was no significant difference between males and females in terms of education status. While $44 \%$ of the male subjects were smokers, only $13.5 \%$ of females smoked $(p<0.001)$. Moreover, a small proportion of participants consumed alcohol (\%8.6).

Table 1. The characteristics of participant

\begin{tabular}{|c|c|c|c|c|}
\hline Variables & Male ( $n=18)$ & Female $(n=52)$ & Total $(n=70)$ & p* \\
\hline Age, years (mean $\pm S D$ ) & $40.2 \pm 10.91$ & $37.0 \pm 9.69$ & $37.8 \pm 10.03$ & 0.250 \\
\hline Body weight, $\mathrm{kg}$ (mean $\pm \mathrm{SD}$ ) & $81.1 \pm 9.34$ & $68.6 \pm 13.89$ & & \\
\hline $\mathrm{BMI}, \mathrm{kg} / \mathrm{m}^{2}$ (mean $\left.\pm \mathrm{SD}\right)$ & $27.1 \pm 2.97$ & $26.6 \pm 5.81$ & & \\
\hline $\begin{array}{l}\text { Waist circumference, } \mathrm{cm} \\
\text { (mean } \pm \text { SD) }\end{array}$ & $97.1 \pm 11.06$ & $88.8 \pm 14.56$ & & \\
\hline $\begin{array}{l}\text { Hip circumference, } \mathrm{cm} \\
\text { (mean } \pm S D)\end{array}$ & $106.7 \pm 11.84$ & $105.1 \pm 11.49$ & & \\
\hline $\begin{array}{l}\text { Marital status, \% } \\
\text { Married } \\
\text { Single }\end{array}$ & $\begin{array}{l}66.7 \\
33.3\end{array}$ & $\begin{array}{l}69.2 \\
30.8\end{array}$ & $\begin{array}{l}68.6 \\
31.4\end{array}$ & \\
\hline Diagnosis time of IBS, month & $2.3 \pm 2.93$ & $7.9 \pm 20.04$ & $6.5 \pm 17.47$ & 0.385 \\
\hline IBS-C, \% & 33.3 & 38.5 & 37.1 & $\begin{array}{c}x 2=0.219 \\
0.896\end{array}$ \\
\hline IBS-D, \% & 22.2 & 23.1 & 22.9 & \multirow{3}{*}{$\begin{array}{c}x 2=14.914 \\
0.000\end{array}$} \\
\hline IBS-M, \% & 44.4 & 38.5 & 40.0 & \\
\hline Smokers, \% & 44 & 13.5 & 21.4 & \\
\hline Alcohol drinkers, \% & 16.7 & 5.8 & 8.6 & $\begin{array}{c}x 2=2.026 \\
0.158\end{array}$ \\
\hline
\end{tabular}

BMI: Body mass index; IBS: Irritable bowel disease; C: constipation, D: diarrhea, M: mixed

*Mann Whitney $U$ and Chi-Square Test

The mean daily intake $( \pm S D$ ) for energy, macronutrients, and selected micronutrients for males and females with IBS were presented in Table 2. The mean intake of energy, protein, carbohydrate, saturated fatty acid, vitamin $B_{1}$, vitamin $B_{2}$, vitamin $B_{6^{\prime}}$ vitamin $B_{12^{\prime}}$ calcium, magnesium, phosphorus, iron, copper $(p<0.001)$, total folic acid, carotene, sodium, and potassium $(p<0.05)$ showed statistically significant differences according to gender. The mean energy intake was $2302.5 \pm 895.6 \mathrm{kcal} /$ day in male patients, whereas, $1485.5 \pm 513.92 \mathrm{kcal} /$ day in female patients $(p<0.01)$. The mean protein intake was $88.1 \pm 34.5 \mathrm{~g} /$ day in male patients and $47.2 \pm 16.72 \mathrm{~g} /$ day in female patients $(p<0.001)$. The average daily intake of nutrients as carbohydrates, saturated fatty acids, vitamin $B_{1}$, vitamin $B_{2}$, vitamin $B_{6}$, vitamin $B_{12}$, calcium, magnesium, phosphorus, iron, copper, total folic acid, carotene, sodium, and potassium was found to be higher in males as compared to females. The mean intake of the other nutrients has been given in Table 2 according to gender. There is no significant difference in terms of gender $(p>0.05)$. Also, there was no significant difference in the dietary intake between the 3 IBS subtypes (no IBS subtypes specific data were shown). 
Table 2. Daily energy and nutrient intake of the study population (mean $\pm S D$ )

\begin{tabular}{|c|c|c|c|}
\hline Total daily intakes & Male (n=18) & Female $(n=52)$ & $\mathbf{P}$ \\
\hline Energy (kcal) & $2302.5 \pm 895.6$ & $1485.5 \pm 513.92$ & $<0.001 * * *$ \\
\hline Total protein (g) & $88.1 \pm 34.5$ & $47.2 \pm 16.72$ & $<0.001 * * *$ \\
\hline Total protein (\%) & $16.2 \pm 6.0$ & $13.4 \pm 2.86$ & 0.142 \\
\hline Total fat (g) & $88.2 \pm 37.7$ & $65.3 \pm 26.25$ & 0.353 \\
\hline Total fat (\%) & $35.1 \pm 7.10$ & $39.9 \pm 9.19$ & 0.054 \\
\hline Carbohydrate (g) & $284.5 \pm 135.6$ & $170.4 \pm 72.84$ & $0.002 * * *$ \\
\hline Carbohydrate (\%) & $48.7 \pm 10.5$ & $46.8 \pm 9.46$ & 0.282 \\
\hline Fiber (g) & $21.8 \pm 10.7$ & $14.6 \pm 5.39$ & 0.015 \\
\hline Saturated fatty acid (g) & $29.3 \pm 8.02$ & $23.2 \pm 9.69$ & $0.008^{* * *}$ \\
\hline $\operatorname{MUFA}(\mathrm{g})^{*}$ & $29.5 \pm 11.81$ & $22.1 \pm 9.29$ & 0.135 \\
\hline PUFA $(g)^{* *}$ & $23.4 \pm 21.43$ & $15.7 \pm 10.03$ & 0.135 \\
\hline Omega6/Omega3 & $17.5 \pm 10.3$ & $13.9 \pm 7.41$ & 0.135 \\
\hline Cholesterol (mg) & $295.9 \pm 156.10$ & $202.2 \pm 135.45$ & 0.013 \\
\hline Vitamin A (mcg) & $1927.6 \pm 3582.38$ & $844.6 \pm 462.03$ & 0.135 \\
\hline Vitamin D (mcg) & $0.7 \pm 0.84$ & $0.7 \pm 0.67$ & 0.337 \\
\hline Carotene (mg) & $3.5 \pm 3.55$ & $2.8 \pm 2.07$ & $0.018^{* * * *}$ \\
\hline Vitamin E (mg) & $19.3 \pm 20.82$ & $13.9 \pm 7.11$ & 0.135 \\
\hline Vitamin $B_{1}(\mathrm{mg})$ & $1.0 \pm 0.41$ & $0.6 \pm 0.20$ & $<0.001 * * *$ \\
\hline Vitamin $B_{2}$ (mg) & $1.5 \pm 0.79$ & $0.9 \pm 0.33$ & $<0.001^{* * *}$ \\
\hline Niacin (mg) & $17.6 \pm 11.7$ & $16.6 \pm 7.30$ & 0.080 \\
\hline Vitamin $B_{6}(\mathrm{mg})$ & $1.5 \pm 0.56$ & $1.1 \pm 0.36$ & $0.001 * * *$ \\
\hline Vitamin $B_{12}(\mathrm{mcg})$ & $7.6 \pm 12.95$ & $2.4 \pm 1.67$ & $0.009 * * *$ \\
\hline Total Folic Acid (mcg) & $366.8 \pm 181.59$ & $240.5 \pm 85.59$ & $0.012 * * * *$ \\
\hline Vitamin C (mg) & $59.7 \pm 41.67$ & $85.0 \pm 45.86$ & 0.053 \\
\hline Sodium (mg) & $2253.7 \pm 1235.97$ & $1451.7 \pm 722.34$ & $0.014^{* * * *}$ \\
\hline Potassium (mg) & $2173.7 \pm 719.62$ & $1757.8 \pm 641.75$ & $0.020 * * * *$ \\
\hline Calcium (mg) & $593.8 \pm 220.63$ & $452.3 \pm 183.59$ & $0.010 * * *$ \\
\hline Magnesium (mg) & $227.9 \pm 76.63$ & $175.9 \pm 71.57$ & $0.004^{* * *}$ \\
\hline Phosphorus (mg) & $1246.4 \pm 346.27$ & $776.1 \pm 263.77$ & $0.000 * * *$ \\
\hline Iron (mg) & $12.8 \pm 5.93$ & $8.4 \pm 2.99$ & $0.004 * * *$ \\
\hline Zinc (mg) & $12.1 \pm 5.43$ & $6.6 \pm 2.27$ & 0.064 \\
\hline Copper (mg) & $1.7 \pm 0.89$ & $1.1 \pm 0.41$ & $0.004^{* * *}$ \\
\hline
\end{tabular}

*Monounsaturated fatty acid ${ }^{* *}$ Polyunsaturated Fatty Acid ${ }^{* * *} p<0.01$. ${ }^{* * * *} p<0.05$. Mann Whitney U

The amount of consumption of food groups was shown in Table 3 according to gender. Consumption of fats, poultry, nuts and seeds, and citrus fruits were significantly higher in males as compared to females $(p<0.05)$. The consumption amounts of other food groups according to gender were given in Table 3 and no significant difference was found between the groups ( $p>0.05)$.

The distribution of nutrients causing sitophobia in individuals has been given in Table 4. It was determined that $85.7 \%$ of the patients had sitophobia and this ratio was $66.7 \%$ in males and $92.3 \%$ in females. The foods causing sitophobia in the males were spicy foods (38.9\%), raw vegetables-fruits $(27.8 \%)$ and legumes (27.8\%) and in females, it was raw vegetables-fruits (38.5\%), piquant foods (32.7\%), legumes (26.9\%) and dairy products $(25.0 \%)$, respectively. It was determined that $35.7 \%$ of all the individuals were uncomfortable with raw vegetablesfruits, $34.3 \%$ with spicy foods and $27.1 \%$ with legumes.
More than half of the individuals (62.9\%) stated that no food alleviated the symptoms of IBS. Among all foods, apricot was considered to be effective in alleviating the symptoms in both genders followed by yoghurt $8.6 \%$; milk $7.1 \%$; olive oil 4.3\%; apple $2.9 \%$; dry plum $2.9 \%$; dried fig $1.4 \%$, leek $1.4 \%$, watermelon $1.4 \%$ and potato $1.4 \%$ (Table 5 ). In addition, pre-and post-diagnosis food frequency questionnaire of the participants was evaluated. There were no significant changes in male pre-and post-diagnosis food frequency questionnaire except for yoghurt. At the post-diagnosis period, females participants' consumption of yoghurt, dried fruit, whole-grain bread, and bran bread increased, whereas consumption of milk, citrus fruits, apples, peaches, quince, bananas, fries, sugar, coffee, carbonated drinks, and white bread decreased (No food frequency questionnaire specific data were shown). 
Table 3. The amount of the distribution of food consumption regarding the individuals' gender

\begin{tabular}{|c|c|c|c|}
\hline & Male & Female & \\
\hline Food groups & $\overline{\mathrm{X}} \pm \mathrm{SD}$ & $\overline{\mathrm{X}} \pm \mathrm{SD}$ & $p$ \\
\hline \multicolumn{4}{|l|}{ Meat group (g) } \\
\hline Red meat & $45.9 \pm 98.90$ & $45.9 \pm 55.26$ & 0.360 \\
\hline Poultry & $40.4 \pm 36.94$ & $36.3 \pm 77.74$ & $0.011 *$ \\
\hline Fish & $2.8 \pm 11.79$ & $1.1 \pm 4.53$ & 0.987 \\
\hline Egg & $28.3 \pm 29.46$ & $20.2 \pm 28.44$ & 0.082 \\
\hline Legumes & $11.7 \pm 14.48$ & $9.5 \pm 15.58$ & 0.308 \\
\hline Oil seeds & $8.9 \pm 16.03$ & $3.5 \pm 11.29$ & $0.023^{*}$ \\
\hline \multicolumn{4}{|l|}{ Milk group (g) } \\
\hline Milk, yoghurt & $101.8 \pm 94.24$ & $97.3 \pm 92.91$ & 0.674 \\
\hline Cheese & $32.4 \pm 26.62$ & $46.3 \pm 34.32$ & 0.128 \\
\hline \multicolumn{4}{|l|}{ Cereals (g) } \\
\hline White bread & $131.2 \pm 129.6$ & $128.0 \pm 149.93$ & 0.535 \\
\hline Brown bread & $15.2 \pm 24.89$ & $38.9 \pm 51.65$ & 0.172 \\
\hline Other cereals & $48.1 \pm 37.22$ & $54.1 \pm 75.27$ & 0.691 \\
\hline \multicolumn{4}{|l|}{ Fruits (g) } \\
\hline Citrus & $20.2 \pm 41.09$ & $0.25 \pm 1.27$ & $0.000 *$ \\
\hline $\begin{array}{l}\text { Apple, peach, } \\
\text { quince, banana }\end{array}$ & $83.4 \pm 77.76$ & $169.2 \pm 201.89$ & 0.364 \\
\hline \multicolumn{4}{|l|}{ Vegetables (g) } \\
\hline $\begin{array}{l}\text { Dark green leafy } \\
\text { vegetables }\end{array}$ & $60.7 \pm 51.63$ & $53.9 \pm 66.94$ & 0.255 \\
\hline $\begin{array}{l}\text { Potatoes, } \\
\text { zucchini, carrots } \\
\text { etc. }\end{array}$ & $201.4 \pm 115.99$ & $291.2 \pm 181.51$ & 0.064 \\
\hline \multicolumn{4}{|l|}{ Oils (g) } \\
\hline Vegetable oils & $32.3 \pm 16.17$ & $21.6 \pm 20.77$ & $0.002^{*}$ \\
\hline Animal fats & $3.6 \pm 4.05$ & $3.1 \pm 5.68$ & 0.198 \\
\hline $\begin{array}{l}\text { Sugar and } \\
\text { similar foods (g) }\end{array}$ & $28.6 \pm 31.42$ & $27.2 \pm 42.70$ & 0.225 \\
\hline
\end{tabular}

${ }^{*} p<0.05$. Mann Whitney $U$ test

Table 4. The distribution of the foods causing sitophobia in individuals

\begin{tabular}{|c|c|c|c|c|c|c|}
\hline \multirow[b]{2}{*}{ Sitophobia status } & \multicolumn{2}{|c|}{ Male (n=18) } & \multicolumn{2}{|c|}{ Female $(n=52)$} & \multicolumn{2}{|c|}{ Total $(n=70)$} \\
\hline & $\mathrm{N}$ & $\%$ & $\mathbf{N}$ & $\%$ & $\mathbf{N}$ & $\%$ \\
\hline Yes & 2 & 66.7 & 48 & 92.3 & 60 & 85.7 \\
\hline No & 6 & 33.3 & 4 & 7.7 & 10 & 14.3 \\
\hline $\begin{array}{l}\text { The foods causing } \\
\text { sitophobia }\end{array}$ & N & $\%$ & N & $\%$ & N & $\%$ \\
\hline Dairy products & 2 & 11.1 & 13 & 25.0 & 15 & 21.4 \\
\hline $\begin{array}{l}\text { Raw fruits and } \\
\text { vegetables }\end{array}$ & 5 & 27.8 & 20 & 38.5 & 25 & 35.7 \\
\hline Cereals & 2 & 11.1 & 9 & 17.3 & 11 & 15.7 \\
\hline Legumes & 5 & 27.8 & 14 & 26.9 & 19 & 27.1 \\
\hline Sugar and sweets & 1 & 5.6 & 6 & 11.5 & 7 & 10.0 \\
\hline Fat and fatty foods & 2 & 11.1 & 12 & 23.1 & 14 & 20.0 \\
\hline $\begin{array}{l}\text { Fizzy drink and } \\
\text { caffeinated beverages }\end{array}$ & 3 & 16.7 & 5 & 9.6 & 8 & 11.4 \\
\hline Spicy foods & 7 & 38.9 & 17 & 32.7 & 24 & 34.3 \\
\hline Spices & 3 & 16.7 & 5 & 9.6 & 8 & 11.4 \\
\hline
\end{tabular}

*Individuals responded to the question more than one and the percentages were calculated according to " $n$ " numbers.
Table 5. The distribution of the participants regarding the foods that they think reduce their symptoms

\begin{tabular}{|c|c|c|c|c|c|c|}
\hline & \multicolumn{2}{|c|}{ Male ( $n=18)$} & \multicolumn{2}{|c|}{ Female $(n=52)$} & \multicolumn{2}{|c|}{ Total $(n=70)$} \\
\hline $\begin{array}{l}\text { Foods reducing } \\
\text { symptoms }\end{array}$ & N & $\%$ & $\mathbf{N}$ & $\%$ & $\mathbf{N}$ & $\%$ \\
\hline Yes & 7 & 38.9 & 19 & 36.5 & 26 & 37.1 \\
\hline No & 11 & 61.1 & 33 & 63.5 & 44 & 62.9 \\
\hline Foods & $\mathbf{N}$ & $\%$ & $\mathrm{~N}$ & $\%$ & $\mathbf{N}$ & $\%$ \\
\hline Dried apricots & 3 & 16.7 & 6 & 11.5 & 9 & 12.9 \\
\hline Yoghurt & 2 & 11.1 & 4 & 7.7 & 6 & 8.6 \\
\hline Milk & 2 & 11.1 & 3 & 5.8 & 5 & 7.1 \\
\hline Olive oil & 1 & 5.6 & 2 & 3.9 & 3 & 4.3 \\
\hline Apple & - & - & 2 & 3.9 & 2 & 2.9 \\
\hline Dried plum & 1 & 5.6 & 1 & 1.9 & 2 & 2.9 \\
\hline Dry fig & - & - & 1 & 1.9 & 1 & 1.4 \\
\hline Leek & - & - & 1 & 1.9 & 1 & 1.4 \\
\hline Watermelon & 1 & 5.6 & - & - & 1 & 1.4 \\
\hline Potato & 1 & 5.6 & - & - & 1 & 1.4 \\
\hline
\end{tabular}

\section{DISCUSSION}

Irritable bowel syndrome is a chronic functional bowel disease characterized by lower and upper gastrointestinal symptoms such as a change in bowel habits (1). Although there are many studies on IBS internationally, there is no large-scale research on adult IBS patients in Turkey. This is a cross-sectional study evaluating the dietary intake of patients with IBS and the dietary habits associated with the symptoms.

In adult individuals with IBS, whereas the age of the sample group varies between 20-62 years, the mean age was reported as $39.3 \pm 13.1$ years (19), $46.9 \pm 13.4$ years (20), $33.3 \pm 13.9$ years (21). On the other hand, the mean age of the individuals is $37.8 \pm 10.03$ years in this study, which is similar to the populations in other studies (19-21). Besides, studies reported the prevalence of IBS differs according to gender, there are other research stating that IBS is seen more frequently in females than males. In particular, there is a strong relationship between gender and IBS-C, seen higher in female patients (22). Stress is known to be an important factor in the pathophysiology of the disease and the more common occurrence of IBS in females can be explained by this situation. In studies conducted on IBS patients, the ratio of female to male patients was $2 / 1,3 / 1,5 / 1$ and $8 / 1$. The female/male ratio of this study is $3 / 1$ and has a similar distribution with other studies $(21,23,24)$.

Irritable bowel syndrome is usually divided into 3 subgroups, which are IBS-C, IBS-D, and IBS-M. In a study conducted with IBS patients, it was determined that $44.8 \%$ of the patients were IBS-M, $28.6 \%$ were IBS-D and $26.5 \%$ were IBS-C. In another study, a total of 56 individuals were examined and as a result, it was stated that $61 \%$ of these individuals were IBS-M. It has been stated that IBS-M subtype is seen more frequently and the rate of occurrence varies in the case of IBS-C and IBS-D. IBS subtypes may vary depending on environmental and individual factors $(24,25)$. In this study, $40.0 \%$ of the individuals are IBS-M, $37.1 \%$ of IBS-C and $22.9 \%$ 
of IBS-D. The obtained data were found to be consistent with the literature. The higher incidence of IBS-M subtype may be due to the fact that the symptoms vary depending on mood and seasonal differences.

The mean BMI of the individuals was calculated as $27.1 \pm 2.97$ $\mathrm{kg} / \mathrm{m}^{2}$ for males and $26.6 \pm 5.81 \mathrm{~kg} / \mathrm{m}^{2}$ for females, respectively. When the obtained data were compared with the mean values obtained in Turkey, the BMI was higher in male subjects while it was found to be lower in female subjects. This may be explained by the fact that the individuals involved in the study did not have adequate knowledge about balanced nutrition and did not restrict the amount of some foods even if they aggravated their IBS symptoms.

The assessment of the nutritional status of individuals is an indication of the extent to which the nutritional requirements are met. Providing a balance between nutrient intake and nutrient requirements is important for optimal health (26). In addition to providing adequate and balanced nutrition in GIS diseases such as irritable bowel syndrome, the importance of medical nutrition therapy is a major factor in increasing QoL. In this context, a low FODMAP diet has been applied in the medical nutrition therapy of IBS in recent years. The low FODMAP diet is based on the principle of reducing fermented oligosaccharides, disaccharides, monosaccharides, and polyols in the diet. Therefore, it refers to all short-chain carbohydrates. Short-chain carbohydrates have low intestinal absorption and they increase symptoms of IBS as they are fermented fast $(10,11)$.

In the current study, the percent of energy from the macronutrients in male and female subjects was as follows: carbohydrate $48.7 \pm 10.5 \%$ and $46.8 \pm 9.46 \%$, protein $16.2 \pm 6.0$ and $13.4 \pm 2.86 \%$, fat $35.1 \pm 7.1 \%$ and $39.9 \pm 9.19 \%$, respectively. Böhn et al. reported that the distribution of macronutrient percentage in the diet of IBS patients was as follows; $47 \pm 8 \%$ carbohydrate, $17 \pm 3 \%$ protein, and $35 \pm 7 \%$ fat (27). In both studies, the patients with IBS had a high fat intake while the carbohydrate intake was low and protein intake was close to the recommended level. When examined the food frequency questionnaire of the individuals in this study, it was seen that the fat sources such as butter and fried foods are frequently consumed which resulted in a high-fat ratio. When studies in the literature were examined, it was seen that IBS patients generally have adequate energy intake and nutrients, as well as energy and nutrient intake, were similar when compared to healthy groups $(21,28)$.

As much as the percentage of energy from fat, the fatty acid composition of the diet is also important. When compared to saturated fat, unsaturated fatty acids such as monounsaturated fatty acids (MUFA) and polyunsaturated fatty acids (PUFA) can reduce total cholesterol and lowdensity lipoprotein-cholesterol (LDL-C) (29). In this study, it was determined that the total amount of fat, saturated fat, MUFA, and PUFA intake of male subjects was higher than that of the females. In line with this, it was revealed that males consumed animal-derived foods such as butter, red meat, vegetable oils such as sunflower oil, and oilseeds more than females.

Dairy products, an item restricted in the FODMAP diet due to lactose content, frequently increase complaints in IBS patients. However, the frequency of lactose intolerance in IBS patients was found to be similar to the healthy population. Lactose increased gas production in the intestine and aggravated symptoms in IBS patients. On the other hand, the consumption of dairy products containing probiotics is thought to have positive effects on IBS patients. In the studies, the intake of calcium and magnesium in IBS patients was found to be lower than the Recommended Dietary Allowance (RDA) (30-32). Similarly, in the present study, calcium and magnesium intake was below the recommended value. When the food consumption of the patients was examined, it was seen that calcium and magnesium sources such as milk, green leafy vegetables and whole grains were consumed insufficiently. With an inadequate intake of calcium and magnesium, patients with high phosphorus uptake may experience mineral homeostasis and deterioration in bone structure (28).

In a study conducted in Norway, it was reported that IBS patients consumed a daily mean of $86.0 \mathrm{~g}$ fresh fruit, 150.5 $\mathrm{g}$ fresh vegetables, $123.5 \mathrm{~g}$ potatoes, 2.2 portions of milk and dairy products, $180 \mathrm{~mL}$ carbonated beverages, 420 $\mathrm{mL}$ coffee and $170 \mathrm{~mL}$ of tea (23). When compared with the results of this study, it was found that fresh vegetable consumption amount was similar, the consumption of fresh fruit was higher whereas the consumption of milk and dairy products was lower. As the regional and cultural differences in nutrition differ from society to society, the consumption amounts can be different depending on this.

Studies have shown that the intake of dietary fiber of IBS patients was below the recommended values $(27,28)$. In this study, it was also found that IBS patients had below the recommended amount of dietary fiber intake. Since patients did not consume sources of fiber such as fresh vegetables and fruits, legumes, whole grain products, etc. in sufficient quantities, the intake of dietary fiber was low.

Besides, the majority of the participants (72.9\%) did not adequately consume fiber sources (e.g. dry legumes) due to worsening of their IBS symptoms. There is no specific fiber recommendation for IBS patients. The amounts determined according to the DRI are also true of IBS patients ( $38 \mathrm{~g} /$ day for adult males and $25 \mathrm{~g} /$ day for adult females) (33). Although there is no clear recommendation for soluble and insoluble fiber, it was stated in a report of the American Dietetic Association in 2008 that the intake of 2-8 g/day of soluble fiber had beneficial effects on health (34).

Although soluble fiber is known to have a beneficial effect on IBS, insoluble fiber such as whole-grain wheat products and wheat bran worsens the symptoms. For this reason, insoluble fiber sources are only recommended for IBS-C patients. Other than IBS patients with acute diarrhea, it is suggested that fiber sources should be included in diets to 
meet the recommended amounts for other IBS patients, and fiber supplementation should be provided in cases that cannot be met by dieting (35-37). FODMAPs draw water into the intestine, that is, they are osmotic. Therefore, when foods containing high FODMAP are consumed, they can be fermented by bacteria in the intestinal system, depending on problems such as poor digestion or poor absorption. This fermentation causes such problems as gas, abdominal pain, cramps, diarrhea, etc. In recent years, it has been suggested that foods rich in FODMAP such as legumes, wheat, rye, apples should be removed from the diet of IBS patients (11, 38).

Although there is no information in the literature on the presence of sitophobia in patients with irritable bowel syndrome, it was reported that in some intestinal diseases, it could decrease food consumption and result in loss of body weight (39). In this study, the sitophobia status of the patients was questioned and it was determined that $85.7 \%$ of the individuals complained of the problem. Foods causing sitophobia were raw vegetables-fruits (35.7\%), piquant foods (34.3\%), and legumes (27.1\%). When the food consumption was examined, it was seen that individuals continued to consume some foods even though they cause sitophobia.

Crohn's \& Colitis Foundation of America reported that probiotics and prebiotics taken with dietary sources (fermented dairy products like yoghurt, non-fermented dairy products) and supplements have beneficial effects in IBS and inflammatory bowel disease but there is no strong evidence on this topic (40). In this study, the participants were asked if there were any foods which they thought alleviated their symptoms and $37.1 \%$ of them replied in positive. The ones who provided a positive reply stated that mostly dried apricots, yoghurt, milk and olive oil reduce their symptoms. As the symptoms and findings of IBS patients vary from person to person, there is no definitive information about the foods that reduce or recover the symptoms (27).

When the studies conducted on IBS patients in different societies are examined, they do not include evidence-based data. The general nutritional recommendation for IBS is as follows: reducing lactose, FODMAPs, fat and fat sources, and foods containing gas constituents, and increasing or decreasing dietary fiber according to IBS subtype. It is known that patients often have various restrictions depending on their symptoms and medical nutrition therapy. However, it was reported that there was not much difference between healthy individuals and IBS patients in terms of dietary intake. On the other hand, it was stated that the reason for higher energy and nutrients intake of IBS patients was to consume the foods which did not influence their symptoms more to compensate for the foods that increase their symptoms (21, 41, 42).

\section{CONCLUSION}

In this study, the energy, macro, and micronutrient intake of IBS individuals were assessed using a 3-day food intake record.
Besides, foods that increase the symptoms of individuals and the foods that reduce their symptoms were questioned. This study is considered as unique as no studies are evaluating IBS patients in Turkish society in this way. The intake of energy and nutrients of the patients with IBS are similar to those of Turkish society in general. However, folate, folic acid, potassium, calcium and magnesium intake is low in the majority of the patients. Furthermore, there was sitophobia in the majority of individuals, and half of them stated that there was no food that reduces their symptoms. Future research should be planned with a larger number of samples and foods could be questioned more comprehensively. In this way, the nutrient-symptom mechanisms can be understood more clearly.

Ethics Committee Approval: This study protocol was examined by Gazi University Ethics Commission and approved by report number 77082166-604.01.02 - on 13.01.2016. Besides, necessary permissions were obtained from the General Secretariate of the $1^{\text {st }}$ Regional Public Hospitals Association of Ankara and Ankara Numune Training and Research Hospital to carry out the study. All the patients who participated in the study were informed about the research and they signed Gazi University Non-Interventional Clinical Trials voluntary form.

Author contributions: Yılmaz B and Akbulut G contributed equally to planning the research analyzing the data and writing the manuscript. Yilmaz B collected the data and Akbulut $G$ reviewed the manuscript with constructive criticisms.

\section{REFERENCES}

[1] Baykan AR, Kasap E, Gerçeker E, Yüceyar, H. Irritable bowel syndrome and genetics. Current Gastroenterology 2012;16:53-55.

[2] Ford AC, Vandvik PO. Irritable bowel syndrome: dietary interventions. Clinical Evidence 2015;7:1-13.

[3] Talley NJ, Zinsmeister A.R, Van Dyke C, Melton LJ. Epidemiology of colonic symptoms and the irritable bowel syndrome. Gastroenterology 1991;101:927-934.

[4] Drossman DA, Li Z, Andruzzi E. U.S. householder survey of functional gastrointestinal disorders. Prevalence, sociodemography, and health impact. Digestive Diseases and Sciences 1993;38:1569-1580.

[5] Kumano H, Kaiya H, Yoshiuchi K, Yamanaka G, Sasaki T, Kuboki T. Comorbidity of irritable bowel syndrome, panic disorder, and agoraphobia in a Japanese representative sample. The American Journal of Gastroenterology 2004;99:370-376.

[6] Şimşek I, Şengül B. Irritable bowel syndrome. Actual Medical Journal 2004;9:60-4.

[7] Karaman N, Türkay C, Yönem O. Irritable bowel syndrome prevalance in city center of Sivas. Turk J. Gastroenterol. 2003;14:128-31.

[8] Çelebi S, Acık Y, Deveci SE, et al. Epidemiological features of irritable bowel syndrome in a Turkish urban society. J Gastroenterol Hepatol 2004;19:738-43.

[9] Mansueto P, Seidita A, D'Alcamo A, Carroccio, A. Role of FODMAPs in patients with irritable bowel syndrome. Nutrition in Clinical Practice 2015;30:665-682. 
[10] Gibson PR, Shepherd SJ. Personal view: food for thoughtwestern lifestyle and susceptibility to Crohn's disease. The FODMAP hypothesis. Alimentary Pharmacology and Therapeutics 2005;21:1399-1409.

[11] Çelebi F, Akbulut G. Current Dietary Approaches in Bowel Diseases: Low Fermentable Oligo-, $\mathrm{Di}$ - and Mono-Saccharides and Polyols (FODMAP) Diet: Review. Turkiye Klinikleri Journal of Gastroenterohepatology 2014;21:43-52.

[12] Halmos EP, Christophersen CT, Bird AR, Shepherd SJ, Gibson PR, Muir JG. Diets that differ in their FODMAP content alter the colonic luminal microenvironment. Gut 2015;64:93-100.

[13] Mazzawi T, Hausken T, Gundersen D, El-Salhy M. Effect of dietary management on the gastric endocrine cells in patients with irritable bowel syndrome. European Journal of Clinical Nutrition 2015;69:519-524.

[14] Mazzawi T, Gundersen D, Hausken T, El-Salhy M. Increased gastric chromogranin A cell density following changes to diets of patients with irritable bowel syndrome. Molecular Medicine Reports 2014;10:2322-2326.

[15] WHO expert consultation. Appropriate body-mass index for Asian populations and its implications for policy and intervention strategies. The Lancet 2004;363: 157-163.

[16] Pekcan G. Determination of nutritional status. Baysal A, Aksoy M, Besler, T, Bozkurt N, Keçecioğlu S, Mercanlıgil SM, KutluayMerdol T, Pekcan G, Yıldız E, editors. Diyet el kitabı. $5^{\text {th }}$ edition. Ankara. Hatiboğlu Publisher, 2008. p. 67-141.

[17] BEBiS (version 7.2). Ebispro for windows. Germany: Turkish Version Nutrition Information Systems.

[18] SPSS Inc. (2013). Statistical Package for the Social Sciences. Chicago, IL; USA.

[19] Öbekli T. Assessment of gastroesophageal reflux with impedance catheter in patients with irritable bowel syndrome. Istanbul University, Istanbul Faculty of Medicine, İstanbul, Master Thesis. 2014. p.25.

[20] Gültepe A. Relationship between Constipation Predominant Irritable Bowel Syndrome and Menstruel Cycle Hormones. Uludağ University, Faculty of Medicine, Bursa. Master Thesis. 2013. p.15

[21] Williams EA, Nai X, Corfe BM. Dietary intakes in people with irritable bowel syndrome. BMC Gastroenteroloy 2011:11:1-7.

[22] Shiotani A, Miyanishi T, Takahashi T. Sex differences in irritable bowel syndrome in Japanese university students. Journal of Gastroenterology 2006; 41:562-568.

[23] Ligaarden SC, Lydersen S, Farup PG. Diet in subjects with irritable bowel syndrome: a cross-sectional study in the general population. BMC Gastroenterology 2012;12:61.

[24] Williams EA, Stimpson J, Wang D, et al. Clinical trial: a multistrain probiotic preparation significantly reduces symptoms of irritable bowel syndrome in a double-blind placebo-controlled study. Alimentary Pharmacology \& Therapeutics 2009;29:97-103.

[25] Ligaarden SC, Axelsson L, Naterstad K, Lydersen S, Farup PG. A candidate probiotic with unfavourable effects in subjects with irritable bowel syndrome: a randomised controlled trial. BMC Gastroenterology 2010;10:16.
[26] Pekcan G. Determination of nutritional status. Ankara: Ministry of Health Publication; 2011.

[27] Bohn L, Storsrud S, Simren M. Nutrient intake in patients with irritable bowel syndrome compared with the general population. Neurogastroenterology \& Motility 2013; 25:23-30.

[28] Prescha A, Pieczynska J, llow R, et al. Assessment of dietary intake of patients with irritable bowel syndrome. Rocz Panstw Zakl Hig. 2009;60:185-189.

[29] Baysal A. Nutrition. $12^{\text {th }}$ edition. Ankara: Hatipoğlu Publisher; 2009.

[30] Simren M, Mansson A, Langkilde AM. Food-related gastrointestinal symptoms in the irritable bowel syndrome. Digestion 2001;63:108-115.

[31] Young P, Cash BD. Probiotic use in irritable bowel syndrome. Current Gastroenterology Reports 2006;8:321-326.

[32] Dapoigny M, Stockbrugger RW, Azpiroz F. Role of alimentation in irritable bowel syndrome. Digestion 2003;67:225-233.

[33] Internet: Dieatry References Intake URL: http://www. webcitation.org/query?url=https $\% 3 A \% 2 F \% 2 F f n i c$. nal.usda.gov\%2Fsites\%2Ffnic.nal.usda. gov\%2Ffiles\%2Fuploads\%2Frecommended_intakes_ individuals.pdf\&date=2019-04-01 Access date: 01.04.2019.

[34] Slavin JL. Position of the American Dietetic Association: health implications of dietary fiber. Journal of the American Dietetic Association 2008;108:1716-31.

[35] Longstreth GF, Thompson WG, Chey WD, Houghton LA, Mearin F, Spiller RC. Functional bowel disorders. Gastroenterology 2006;130:1480-1491.

[36] Miller V, Lea R, Agrawal A, Whorwell PJ. Bran and irritable bowel syndrome: the primary-care perspective. Digestive and Liver Disease 2006;38:737-740.

[37] Bijkerk CJ, Muris JW, Knottnerus JA, Hoes AW, de Wit NJ. Systematic review: the role of different types of fibre in the treatment of irritable bowel syndrome. Alimentary Pharmacology and Therapeutics 2004;19:245-251.

[38] Gibson PR, Shepherd SJ. Evidence-based dietary management of functional gastrointestinal symptoms: The FODMAP approach. Journal of Gastroenterology and Hepatology 2010;25:252-258.

[39] Thomson ABR, Shaffer EA. (Eds.). First principles of gastroenterology the basis of disease and an approach to management, Fourth Edition. Canada. Astra Pharmaceuticals, 2000. p. 254.

[40] American Crohn's and Colitis Foundation. Inflammatory Bowel Disease and Irritable Bowel Syndrome Similarities and Differences. New York, 2014. p. 6-8.

[41] Shepherd SJ, Gibson PR. Fructose malabsorption and symptoms of irritable bowel syndrome: guidelines for effective dietary management. Journal of the American Dietetic Association 2006;106:1631-1639.

[42] Heizer WD, Southern S, McGovern S. The role of diet in symptoms of irritable bowel syndrome in adults: a narrative review. Journal of the American Dietetic Association 2009;109:1204-1214. 